\title{
THE EFFECT OF BARRIER STRUCTURE ON THE PERFORMANCE OF DOUBLE BARRIER QUANTUM WELL INFRA-RED PHOTODETECTORS
}

\author{
K. L. TSAI, C. P. LEE, P. C. CHEN, J. S. TSANG, C. M. TSAI and J. C. FAN \\ Department of Electronics Engineering and Institute of Electronics, National Chiao Tung University, \\ Hsin-Chu, Taiwan, R.O.China
}

(Received I May 1995; in revised form 9 May 1995)

\begin{abstract}
The effects of the inner and outer barriers on the performance of mid-wavelength $(3-5 \mu \mathrm{m})$ $\mathrm{GaAs} / \mathrm{AlGaAs}$ double barrier quantum well infra-red photodetectors (DBQWIPs) have been studied. It was found that the peak response wavelength had a significant red shift when the thickness of the AlAs inner barriers was below $10 \AA$. This is attributed to the lowering of the upper state energy in the quantum wells. The responsivity of DBQWIPs decreases with the inner barrier thickness. This is because the optical gain decreases faster than the increasing rate of the quantum efficiency when the inner barrier thickness increases. The responsivities for devices with different $\mathrm{Al}$ compositions $(0.35$ and 0.24$)$ in the outer barriers are in the same range, but the dark currents for devices with $\mathrm{Al}_{0.35} \mathrm{Ga}_{0.65} \mathrm{As}$ outer barriers are much lower than those with $\mathrm{Al}_{0.24} \mathrm{Ga}_{0.76} \mathrm{As}$ outer barriers. Nearly two orders of magnitude improvement in detectivity was observed when the Al composition in the outer barriers was changed from 0.24 to 0.35 . A high detectivity of $1 \times 10^{11} \mathrm{~cm} \mathrm{~Hz}^{1 / 2} \mathrm{~W}^{-1}$ at $77 \mathrm{~K}$ was obtained for a device with $12 \AA \mathrm{AlAs}$ inner barriers and $300 \AA \mathrm{Al}_{0.35} \mathrm{Ga}_{0.65} \mathrm{As}$ outer barriers.
\end{abstract}

\section{INTRODUCTION}

There has been a lot of interest in 8-12 $\mu \mathrm{m}$ multiple quantum well infra-red (i.r.) photodetectors (QWIPs) due to the possibility of producing high performance, large area, highly uniform and low cost two-dimensional thermal image arrays[1] as a result of the mature growth and processing technologies of III-V compound materials. There is also increasing interest in photodetectors for the middle-wavelength i.r. $3-5 \mu \mathrm{m}$ regime. However, this wavelength range is not accessible using $\mathrm{GaAs} / \mathrm{AlGaAs}$ multiple quantum well structures. In this material system, in order for the quantum wells to absorb 3-5 $\mu$ m radiation, the $\mathrm{Al}$ content in the barriers has to be higher than $45 \%$. But with such barriers, in which the $\mathrm{X}$ valley energy is lower than that of the $\Gamma$ valley, the thermal activation energy is lower than the optical transition energy, leading to higher dark current and poor temperature performance[2]. Because of this limitation, the minimum obtainable operating wavelength is $5.6 \mu \mathrm{m}[3]$. The $\mathrm{In}_{0.53} \mathrm{Ga}_{0.47} \mathrm{As} / \mathrm{In}_{0.52} \mathrm{Al}_{0.48} \mathrm{As}$ latticematched heterostructure has a conduction-band discontinuity of $\Delta E_{\mathrm{c}}=550 \mathrm{meV}$, which is significantly higher than that of direct $\mathrm{GaAs} / \mathrm{Al}_{x} \mathrm{Ga}_{1-x} \mathrm{As}$ heterostructure and therefore allows a 3-5 $\mu \mathrm{m}$ operation for QWIPs[4]. However, this material has to be grown on InP substrates. Recently, a new type of quantum well i.r. photodetector, shown in Fig. 1, which uses thin inner barriers next to the wells, has been demonstrated[5]. The photo-excited carriers tunnel through the thin barriers and constitute the photo-current. Because the effective barrier height can be easily adjusted, this structure can be applied to middle-wavelength, long-wavelength, or twocolour i.r. photodetectors [5-7].

For a QWIP device, the inter-subband transition is from a bound state to a bound or continuum state. However, in double barrier quantum well i.r. photodetectors (DBQWIPs), the excited state is a quasibound state confined by a pair of thin inner barriers. In general, the responsivity of the detectors increases with the absorption coefficient and the optical gain. The DBQWIPs with thick inner barriers will have a large absorption coefficient, but a poor optical gain. On the other hand, the devices with thin inner barriers will have a large optical gain, but a poor absorption coefficient. Therefore, both the absorption coefficient and the optical gain depend on the design of the inner barriers, which need to be carefully optimized. Another important figure of merit of photodetectors is the dark current. In a DBQWIP, the amount of the dark current is mainly controlled by the outer barriers. However, this effect has not been studied for DBQWIPs. Although devices with absorption in the 3-5 $\mu \mathrm{m}$ band have been fabricated by Schneider $e t$ al.[5], the detectivity of these devices is unknown. These devices have been theoretically analysed by Kiledjian et al.[8]. However, in the analysis, they assumed a unity optical gain, which, as will be seen later in the present paper, is not correct in reality. In this paper, we have studied the effect of 


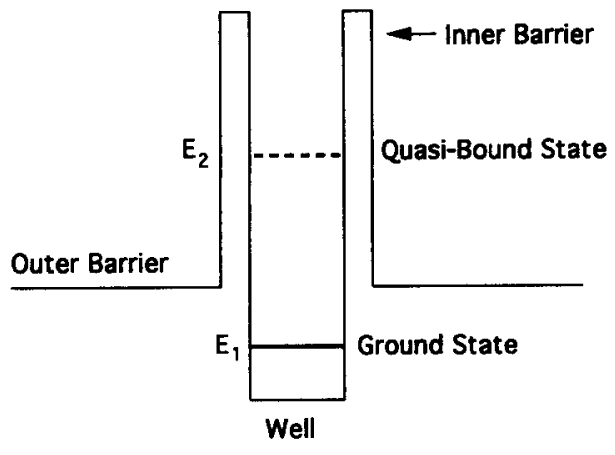

Fig. 1. Structure of the double barrier quantum well i.r. photodetectors.

the inner and outer barriers on the performance of the DBQWIPs, and found the optimum barrier structure.

\section{EXPERIMENTAL}

The QWIP samples were grown by an Intervac Gen II molecular beam epitaxy (MBE) system on (100) semi-insulating GaAs substrates. In order to understand the effect of the inner and outer barriers on the performance of DBQWIPs, we have grown eight samples. Their structures are listed in Table 1. For samples $\mathrm{A}, \mathrm{B}$ and $\mathrm{C}$, the multiple quantum wells, between two $n$-type $\left(n=2 \times 10^{18} \mathrm{~cm}^{-3}\right) 1.0 \mu \mathrm{m}$ contact layers, consisted of 30 periods, with each period consisting of a $50 \AA$ GaAs well (doped to $n=1 \times 10^{18} \mathrm{~cm}^{-3}$ ), a pair of inner AlAs barriers, and an outer $350 \AA \mathrm{Al}_{0.24} \mathrm{Ga}_{0.76}$ As barrier. The thicknesses of the inner barriers were 6,14 and $28 \AA$ for samples A, B and C, respectively. For samples D, E, F, G and $\mathrm{H}$, an outer barrier with a higher $\mathrm{Al}$ content $\left(\mathrm{Al}_{0.35} \mathrm{Ga}_{0.65} \mathrm{As}\right)$ was used, with a thickness of $300 \AA$. The inner barrier thicknesses for these five samples were $8,12,16,20$ and $24 \AA$, respectively. Twenty periods of quantum wells were used for these samples. After MBE growth, $240 \times 420 \mu \mathrm{m}$ mesas were defined by chemical etching down to the $n^{+}$bottom contact layer. To couple the normal incident i.r. radiation, $3.6 \mu \mathrm{m}$ etched stripe gratings were fabricated on the top surface in a $200 \mu \mathrm{m}$ square area. $\mathrm{Au} / \mathrm{Ge}$ was evaporated onto the top of each mesa (except for the grating area) and the $n^{+}$bottom

Table 1. Structure parameters for samples $\mathbf{A}-\mathbf{H}$, including quantum well width $\left(L_{\mathrm{w}}\right)$, inner barrier width $\left(L_{\mathrm{ib}}\right)$, inner barrier $\mathrm{Al}_{x} \mathrm{Ga}_{1-x} \mathrm{As}$ composition $\left(x_{\mathrm{i}}\right)$, outer barrier width $\left(L_{\mathrm{ob}}\right)$, outer barrier $\mathrm{Al}_{x} \mathrm{Ga}_{1}{ }_{x} \mathrm{As}$ composition $\left(x_{0}\right)$ and the number of multi-quantum well periods

\begin{tabular}{ccccccc}
\hline Sample & $\begin{array}{c}L_{\mathrm{w}} \\
(\AA)\end{array}$ & $\begin{array}{r}L_{i \mathrm{~b}} \\
(\AA)\end{array}$ & $X_{\mathrm{i}}$ & $\begin{array}{c}L_{\mathrm{gb}} \\
(\AA)\end{array}$ & $\boldsymbol{X}_{\mathrm{o}}$ & Periods \\
\hline A & 50 & 6 & 1 & 350 & 0.24 & 30 \\
B & 50 & 14 & 1 & 350 & 0.24 & 30 \\
C & 50 & 28 & 1 & 350 & 0.24 & 30 \\
D & 50 & 8 & 1 & 300 & 0.35 & 20 \\
E & 50 & 12 & 1 & 300 & 0.35 & 20 \\
F & 50 & 16 & 1 & 300 & 0.35 & 20 \\
G & 50 & 20 & 1 & 300 & 0.35 & 20 \\
H & 50 & 24 & 1 & 300 & 0.35 & 20 \\
\hline
\end{tabular}

contact layer for ohmic contacts. The QWIPs were tested with i.r. irradiation from the front side. The spectral response of the QWIPs was measured using a current preamplifier and a Nicolet Fourier transform i.r. spectrometer. The responsitivity was measured at $77 \mathrm{~K}$ by the standard lock-in technique using a $800^{\circ} \mathrm{C}$ black-body source chopped at $1 \mathrm{KHz}$. The devices were mounted in a liquid nitrogen cooled optical dewar with a $\mathrm{ZnSe}$ window.

\section{RESULTS AND DISCUSSION}

Figure 2(a) displays the $77 \mathrm{~K}$ spectral responses of samples $A$ and $B$, which had $24 \%$ aluminum content in the outer barriers. The peak wavelength of sample A was centred around $5.2 \mu \mathrm{m}$, and the line width was $2.4 \mu \mathrm{m}$, while the peak wavelength of sample B was centred around $4.5 \mu \mathrm{m}$, and the line width was $0.6 \mu \mathrm{m}$. The spectral response of sample $\mathrm{C}$ (not shown in the figure), which had $28 \AA$ inner barriers, was similar to sample $B$, which had $14 \AA$ inner barriers. Figure 2(b) displays the spectral responses of samples $D, E, F, G$ and $H$, in which the aluminum
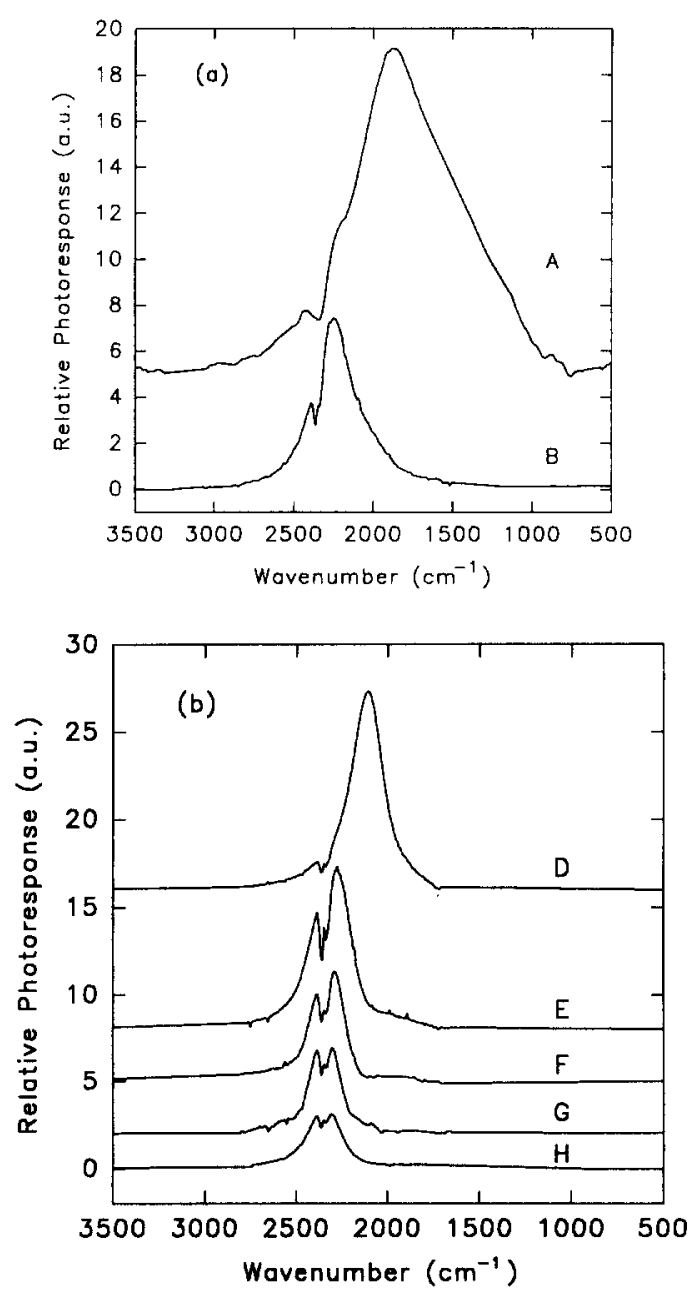

Fig. 2. Spectral response at $77 \mathrm{~K}$ with bias voltage $-1 \mathrm{~V}$ of (a) samples $A$ and $B$, and (b) samples $\mathrm{D}-\mathrm{H}$. 
composition of the outer barrier was 0.35 . The peak wavelength of sample $D$ was centred around $4.8 \mu \mathrm{m}$. The peak wavelengths of $E, F, G$ and $H$ with inner barrier thicknesses of $12,16,20$ and $24 \AA$, respectively, were around $4.3 \mu \mathrm{m}$. The kink at $2381 \mathrm{~cm}^{-1}$ $(4.2 \mu \mathrm{m})$ in all QWIP samples was due to the absorption of $\mathrm{CO}_{2}$ in the optical path. The spectral line shape was insensitive to the applied voltages. In Fig. 2, we found that the peak wavelength shifted towards long wavelengths when the inner barrier thickness was reduced to 8 or $6 \AA$, regardless of whether the aluminum composition of the outer barrier was 0.35 or 0.24 . The shift in absorption energy is due to the change in the position of the (upper) quasi-bound state, which is lower when the inner barriers are thinner. This has been confirmed by calculation using the transfer matrix method, which indicates that the ground state energy stays more or less the same but that the energy of the upper state decreases when the inner barrier thickness becomes very thin.
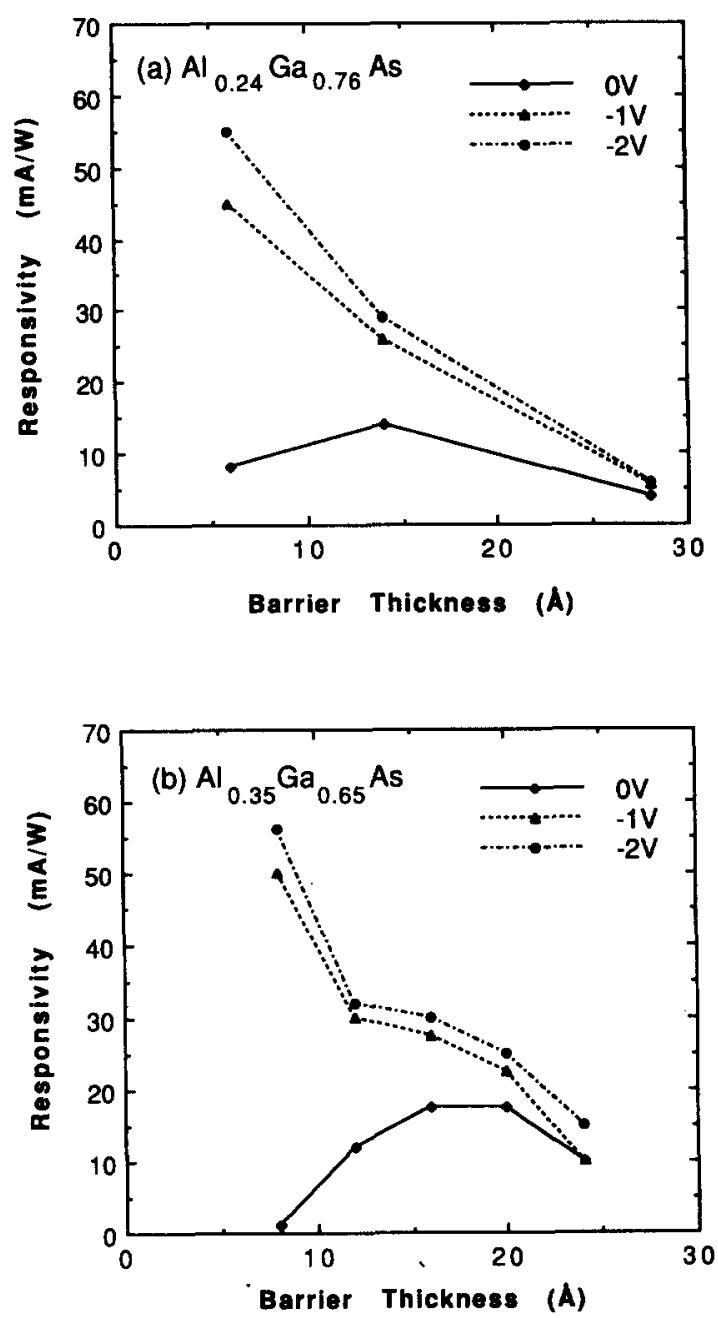

Fig. 3. Peak responsivities vs inner barrier thickness, in which the Al composition of the outer barrier is 0.24 and 0.35 in (a) and (b), respectively.

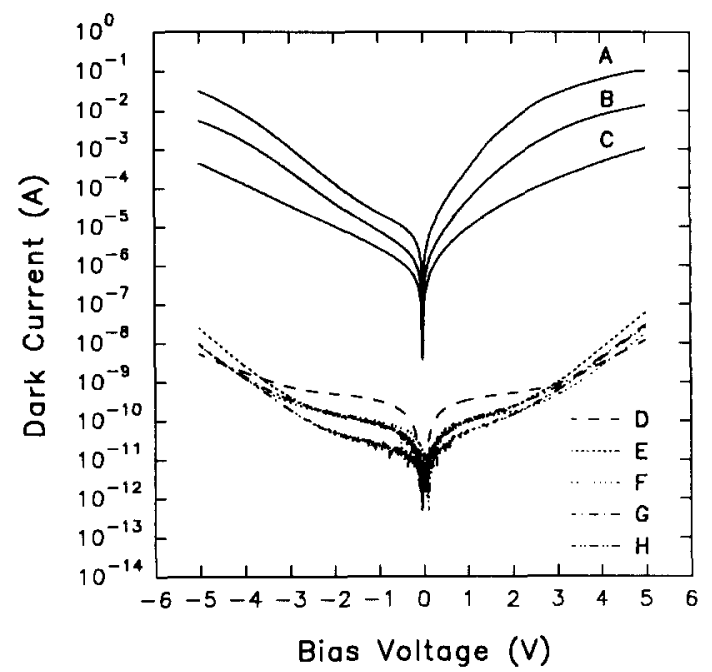

Fig. 4. Dark current of samples A-H measured at $77 \mathrm{~K}$.

Figure 3 shows the peak responsivities vs the inner barrier thickness of DBQWIPs with aluminum composition in the outer barrier being 0.24 and 0.35 . All samples had finite photo-responses at zero bias. This photovoltaic effect, which has also been seen in other reports[5], may be explained by a difference in the AlAs/GaAs interface property above and below each GaAs quantum well, owing to the growth process. The responsivities are in the same range for samples with different $\mathrm{Al}$ content in the outer barriers. The peak responsivity of DBQWIPs decreases when the inner barrier thickness increases. This trend is in contrast to that of the quantum efficiency, which increases with thickness of the inner barriers, due to the increased absorption caused by a better confined upper state. However, the optical gain, another factor that influences the responsivity, decreases with the inner barrier thickness. It is more difficult for the photo-excited electrons to tunnel through the inner barriers when they are thicker, therefore resulting in a lower gain. Since the responsivity is proportional to the product of the quantum efficiency and the optical gain, the decrease of the responsivity with the inner barrier thickness indicates that the optical gain decreases faster than the increasing rate of the quantum efficiency.

Figure 4 shows the dark currents of the eight QWIP samples measured at $77 \mathrm{~K}$ as functions of applied voltage. The dark currents of samples D-H, which had outer barriers with a higher Al content, $\left(\mathrm{Al}_{0.33} \mathrm{Ga}_{0.65} \mathrm{As}\right)$ were much lower than those of samples A-C, which had a lower Al content (0.24) in the outer barriers. The difference in dark current can be explained by the difference in the barrier height that the electrons see. The electrons in the ground state of a quantum well have to tunnel through the triangular potential barrier (when under bias) to constitute the dark current. Because the inner barriers are very thin, the main barrier that the electrons have to go through is the outer barrier. Therefore, when 


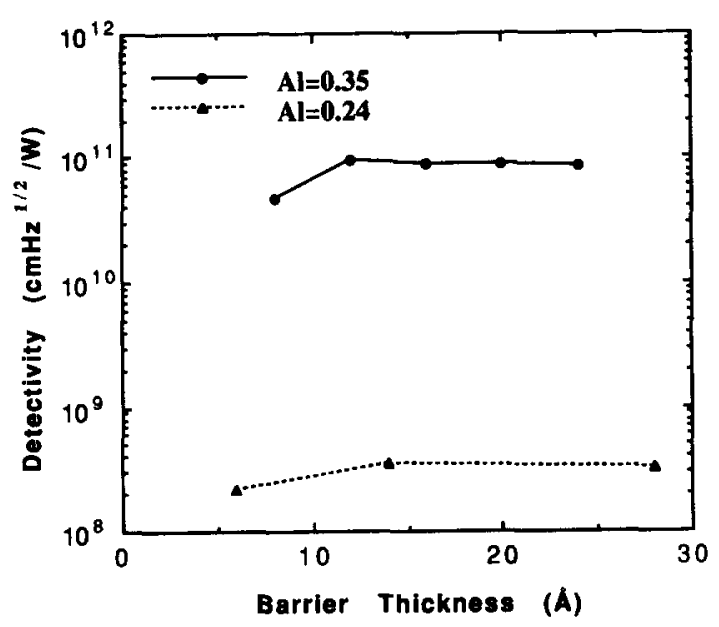

Fig. 5. Relationship between detectivity (at $-1 \mathrm{~V}$ ) and inner barrier thickness for the $\mathrm{Al}_{0.24} \mathrm{Ga}_{0.76} \mathrm{As}$ and the $\mathrm{Al}_{0.35} \mathrm{Ga}_{0.65} \mathrm{As}$ outer barrier systems.

the outer barrier is higher (due to higher $\mathrm{Al}$ content), the dark current is greatly reduced. A more important figure of merit for a detector is the detectivity $\left(D^{*}\right)$, which depends on the responsivity and the dark current. The detectivity can be calculated by[9]:

$$
D^{*}=R\left(A \Delta f N p_{\mathrm{c}}\right)^{1 / 2} /\left(4 e l_{\mathrm{d}}\right)^{1 / 2}
$$

where $R$ is the responsivity, $A$ is the device area, $\Delta f$ is the band width, $N$ is the number of wells, $p_{c}$ is the capture probability, and $l_{\mathrm{d}}$ is the dark current. In general, $p_{\mathrm{c}}$ is estimated to be between 0.04 and 0.1 for a normal quantum well structure[9]. For our sample, we assumed that $p_{\mathrm{c}}$ was 0.1 . In a double barrier quantum well structure, the photo-excited carriers not only need to go through the wells, but also have to tunnel through the thin inner barriers, so it is reasonable that the capture probability in DBQWIPs is larger than that in regular QWIPs. Figure 5 shows the relationship between the detectivity (at $-1 \mathrm{~V}$ ) and the inner barrier thickness. Because the dark current is very low for devices with $\mathrm{Al}_{0.35} \mathrm{Ga}_{0.65} \mathrm{As}$ outer barriers, the detectivities for these devices are much higher than those with $\mathrm{Al}_{0.24} \mathrm{Ga}_{0.76}$ As outer barriers even though they have similar responsivities. $A$ high detectivity of $1 \times 10^{11} \mathrm{~cm} \mathrm{~Hz}^{1 / 2} \mathrm{~W}^{-1}$ (at $77 \mathrm{~K}$ and $-1 \mathrm{~V}$ ) was obtained for DBQWIPs which had $12 \AA$
AlAs inner barriers and $300 \AA \mathrm{Al}_{0.35} \mathrm{Ga}_{0.65} \mathrm{As}$ outer barriers. Nearly two orders of magnitude improvement in detectivity was obtained when the Al content in the outer barriers was changed from 0.24 to 0.35 .

\section{CONCLUSION}

We have studied the effects of the inner and outer barriers on the performance of mid-wavelength DBQWIPs. The responsivity of DBQWIPs was found to decrease when the inner barrier thickness increases. This is because the optical gain decreases at a faster rate than the increasing rate of the quantum efficiency. When the inner barrier thickness in DBQWIPs is the same, the detectivity with the $\mathrm{Al}_{0.35} \mathrm{Ga}_{0.65}$ As outer barrier system is higher than that for the $\mathrm{Al}_{0.24} \mathrm{Ga}_{0.76} \mathrm{As}$ outer barrier system. This is because the dark currents with $\mathrm{Al}_{0.35} \mathrm{Ga}_{0.65}$ As outer barriers are much lower than those with $\mathrm{Al}_{0.24} \mathrm{Ga}_{0.76} \mathrm{As}$ outer barriers. A high detectivity of $1 \times 10^{11} \mathrm{~cm} \mathrm{~Hz}^{1 / 2}$ $\mathrm{W}^{-1}$ at $77 \mathrm{~K}$ was obtained for devices with $12 \AA$ AlAs inner barriers and $300 \AA \mathrm{Al}_{0.35} \mathrm{Ga}_{0.65} \mathrm{As}$ outer barriers.

Acknowledgement - This work is partially supported by the National Science Council of the Republic of China, under contract number NSC83-0404-E009-092.

\section{REFERENCES}

1. C. G. Bethea, B. F. Levine, M. T. Asom, R. E. Leibenguth, J. W. Stayt, K. G. Glogovsky, R. A. Morgan, J. D. Blackwell and W. J. Parrish, IEEE Trans. Electron Devices 40, 1957 (1993).

2. A. Fiore, E. Rosencher, P. Bois, J. Nagle and N. Laurent, Appl. Phys. Lett. 64, 478 (1994).

3. B. F. Levine, S. D. Gunapala and R. F. Kopf, Appl. Phys. Lett. 58, 1551 (1991).

4. B. F. Levine, A. Y. Cho, J. Walker, R. J. Malik, D. A. Kleinman and D. L. Sivco, Appl. Phys. Lett. 52, 1481 (1988).

5. H. Schneider, F. Fuchs, B. Dischlier, J. D. Ralston and P. Koidl, Appl. Phys. Lett. 58, 2234 (1991).

6. B. F. Levine, A. Zussman, S. D. Gunapala, M. T. Asom, J. M. Kuo, W. S. Hobson, V. O. Shen, R. R. Abbott and S. J. Hseih, J. appl. Phys. 72, 4429 (1992).

7. K. L. Tsai, K. H. Chang, C. P. Lee, K. F. Huang, J. S. Tsang and H. R. Chen, Appl. Phys. Lett. 62, 3504 (1993).

8. M. S. Kiledjian, J. N. Schulman and K. L. Wang, Phys. Rev. B 44, 5616 (1991).

9. H. C. Liu, Appl. Phys. Lett. 60, 1507 (1992). 